ISSN 2525-4804

\title{
DESEMPENHO AGRONÔMICO DO Megathyrsus maximus cv. Mombaça SUBMETIDO A ADUBAÇÃO FOSFATADA COM E SEM CALAGEM EM MANUTENÇÃO
}

\author{
Wanderson Lopes de Sousa ${ }^{1}$; João Pedro da Luz Milhomem²; Jonas de Sousa Pereira ${ }^{3}$; Breno Ricardo \\ dos Santos Pereira ${ }^{4}$; Samuel de Deus da Silva ${ }^{5}$
}

\section{RESUMO:}

A perda de produtividade em pastagens tem sido atribuída a diversos fatores, ao longo do tempo, dentre os quais pode-se destacar a falta de adubação de manutenção e a deficiência de fósforo no solo. Nessa perspectiva, objetivou-se avaliar o desempenho agronômico do Megathyrsus maximus cv. Mombaça submetido a diferentes níveis de adubação com fósforo (P), com e sem calagem em fase de manutenção, sob pastejo, em sistema de média tecnologia, a fim de contribuir com a atividade pecuária mais produtiva e sustentável. O experimento foi conduzido em condições ambientais locais de campo no setor de recria do Instituto Federal de Educação, Ciência e Tecnologia do Tocantins (IFTO) - Campus Araguatins em uma área total de $480 \mathrm{~m}^{2}$. O delineamento experimental utilizado foi o de blocos casualizados (DBC), com quatro repetições, totalizando 32 parcelas experimentais. O experimento foi composto por quatro níveis de fósforo $\left(0,30,80\right.$ e $120 \mathrm{~kg} \mathrm{ha}^{-1}$ de $\left.\mathrm{P}_{2} \mathrm{O}_{5}\right)$, com e sem calagem. As análises estatísticas foram realizadas com o auxílio do software SISVAR. Os resultados das análises laboratoriais e de campo foram submetidos à análise de variância e as médias comparadas pelo teste de Scott-Knott ao nível de 5\% de probabilidade. O M. maximus cv. Mombaça apresentou melhores resultados produtivos com as doses de $80 \mathrm{~kg} \mathrm{ha}^{-1}$ de $\mathrm{P}_{2} \mathrm{O}_{5}$ e $120 \mathrm{~kg} \mathrm{ha}^{-1} \mathrm{de}$ $\mathrm{P}_{2} \mathrm{O}_{5}$, em produção de matéria verde e de matéria seca. A pastagem obteve incremento de produtividade e em porcentagem de matéria seca com a dose de $30 \mathrm{~kg} \mathrm{ha}^{-1}$ de $\mathrm{P}_{2} \mathrm{O}_{5}$ na fase de manutenção, quando precedida da correção do solo com a calagem, nas condições ambientais locais de Cerrado-Amazônia de Araguatins - TO.

Palavras-chave: calcário, fertilidade do solo, forragem, produção.

\footnotetext{
${ }^{1}$ Engenheiro Agrônomo, Mestrado em Produção Vegetal; Universidade Federal do Tocantins - Campus Gurupi; Gurupi - TO; sousawandersonlopes@gmail.com

${ }^{2}$ Engenheiro Agrônomo; Instituto Federal de Educação, Ciência e Tecnologia do Tocantins - Campus Araguatins; Araguatins TO; Joaoluzm95@gmail.com

${ }^{3}$ Engenheiro Agrônomo; Instituto Federal de Educação, Ciência e Tecnologia do Tocantins - Campus Araguatins; Araguatins TO; jonasagronomo@gmail.com

${ }^{4}$ Engenheiro Agrônomo; Instituto Federal de Educação, Ciência e Tecnologia do Tocantins - Campus Araguatins; Araguatins TO; brenoricardopereira@gmail.com

${ }^{5}$ Engenheiro Agrônomo, Doutor em Agronomia; Instituto Federal de Educação, Ciência e Tecnologia do Tocantins - Campus Araguatins; Araguatins - TO; agrosamuel@gmail.com
} 
ISSN 2525-4804

\title{
AGRONOMIC PERFORMANCE OF Megathyrsus maximus cv. Mombasa SUBMITTED TO PHOSPHATE FERTILIZATION WITH AND WITHOUT LIME IN MAINTENANCE
}

\begin{abstract}
:
The loss of productivity in pastures has been attributed to several factors, over time, among which we can highlight the lack of maintenance fertilizer and phosphorus deficiency in the soil. From this perspective, the objective was to evaluate the agronomic performance of Megathyrsus maximus cv. Mombaça submitted to different levels of fertilization with phosphorus $(\mathrm{P})$, with and without liming in the maintenance phase, under grazing, in a medium technology system, in order to contribute to the most productive and sustainable livestock activity. The experiment was carried out under local environmental field conditions in the recreation sector of the Federal Institute of Education, Science and Technology of Tocantins (IFTO) - Campus Araguatins in a total area of $480 \mathrm{~m}^{2}$. The experimental design used was the randomized blocks (DBC), with four replications, totaling 32 experimental plots. The experiment consisted of four levels of phosphorus $(0,30,80$ and $120 \mathrm{~kg} \mathrm{ha}^{-1}$ of $\mathrm{P}_{2} \mathrm{O}_{5}$ ), with and without liming. Statistical analyzes were performed with the aid of the SISVAR software. The results of the laboratory and field analyzes were submitted to variance analysis and means compared by the Scott-Knott test at the level of 5\% probability. M. maximus cv. Mombaça showed better productive results with doses of $80 \mathrm{~kg} \mathrm{ha}^{-1}$ of $\mathrm{P}_{2} \mathrm{O}_{5}$ and $120 \mathrm{~kg} \mathrm{ha}^{-1}$ of $\mathrm{P}_{2} \mathrm{O}_{5}$, in production of green and dry matter. The pasture obtained an increase in productivity and in percentage of dry matter with the dose of $30 \mathrm{~kg} \mathrm{ha}^{-1}$ of $\mathrm{P}_{2} \mathrm{O}_{5}$ in the maintenance phase, when preceded by the correction of the soil with liming, in the local environmental conditions of Cerrado-Amazônia in the city of Araguatins, state of Tocantins.
\end{abstract}

Key words: limestone, soil fertility, forage, production. 
O sistema de produção a pasto tem sido o componente-chave para uma pecuária cada vez mais produtiva e sustentável. Uma vez que as pastagens compreendem uma base alimentar ecologicamente correta, elas são importantes porque disponibilizam oxigênio ao meio ambiente, contribuem com o sequestro de carbono, além de ser alimento de alto valor nutricional para a produção de carne e leite de maneira natural. $\mathrm{O}$ sucesso da atividade pecuária depende, basicamente, de três fatores: produtividade, relação custo-benefício do sistema de produção e o preço de venda da produção (Matsuda 2010). Nessa perspectiva, o Brasil tem se consolidado como um dos principais produtor e exportador mundial de carne bovina nos últimos anos (IBGE, 2017; MAPA 2018; USDA, 2018).

A pecuária ocupa uma das principais atividades do agronegócio brasileiro, destacando-se com um efetivo de 173.000.000 milhões de bovinos, em 2.554.415 estabelecimentos agropecuários. Sendo que desse total, 6.500.000 cabeças encontram-se no Tocantins, revelando-se o terceiro Estado da região Norte e o décimo primeiro com maior rebanho efetivo de bovinos no País (IBGE, 2017). A atividade pecuária tem obtido produções quase que exclusivamente na alimentação a pasto, pois esta é reconhecida, tecnicamente, como uma alternativa para a redução de custos de produção, principalmente em períodos de maior precipitação pluviométrica (Fonseca, Martuscello, 2010).

É necessário adotar o cultivo de espécies forrageiras de elevada produtividade. A gramínea (Poaceae) forrageira Megathyrsus maximus (sin. Panicum maximum) é conhecida mundialmente, pela sua adaptabilidade a diferentes condições edafoclimáticas e excelente qualidade e produtividade de forragem. Essa espécie, é uma das forrageiras tropicais mais produtiva dentre as propagadas por sementes, por isso tem despertado a atenção de técnicos e produtores agropecuários, sobretudo, pela sua produção abundante de folhas, porte elevado e alta aceitabilidade por animais ruminantes e não-ruminantes (Jank et al., 2013).
No Cerrado brasileiro, a perda de produtividade em pastagens tem sido atribuída a diversos fatores, ao longo do tempo, dentre os quais pode-se destacar a falta de adubação de manutenção e a deficiência de fósforo no solo (Vilela et al., 2004). Aliado a isso, algumas informações sobre a resposta dessa forrageira em ambiente de produção do ecótono Cerrado-Amazônia, associadas a diferentes dosagens de fósforo (P), com e sem a correção do solo com calcário, ainda têm sido apresentadas de forma incipiente em âmbito local.

Nessa perspectiva, objetivou-se avaliar o desempenho agronômico do Megathyrsus maximus cv. Mombaça submetido a diferentes níveis de adubação com fósforo (P), com e sem calagem em fase de manutenção, sob pastejo, em sistema de média tecnologia, a fim de contribuir com a atividade pecuária mais produtiva e sustentável.

O experimento foi realizado no setor de Zootecnia III da Unidade Escolar de Produção (UEP), do Instituto Federal de Educação, Ciência e Tecnologia do Tocantins (IFTO) - Campus Araguatins, localizado à uma altitude de $116 \mathrm{~m}$, latitude $05^{\circ} 38^{\prime} 23,9$ ' Sul (S) e longitude $48^{\circ} 04^{\prime}$ 04,9" Oeste (W).

O clima da região de ecótono CerradoAmazônia é do tipo Aw. Conforme a classificação climática de Köppen, essa região apresenta clima tropical com estação seca no inverno (EMBRAPA, 2018). Isso significa que a região apresenta estação chuvosa bem definida predominante entre os meses de novembro a abril, e com estação seca de maio a outubro (INMET, 2018).

O local de desenvolvimento do trabalho foi no setor de recria, em uma área experimental de $20 \mathrm{~m}$ de largura por $24 \mathrm{~m}$ de comprimento, resultando em uma área total de 480 $\mathrm{m}^{2}$. As parcelas experimentais foram constituídas de $3 \mathrm{~m}$ de comprimento por $5 \mathrm{~m}$ de largura, as quais totalizaram uma área de $15 \mathrm{~m}^{2}$, individualmente.

Os cortes na forragem foram realizados a partir do terceiro mês (fevereiro de 2018) do início do experimento, após a aplicação de calcário na área, 
conforme recomendações baseadas na análise do solo.

O experimento foi conduzido em condições ambientais locais de campo no município Araguatins - TO, entre novembro de 2017 e abril de 2018, período em que o Megathyrsus maximus cv. Mombaça foi submetido aos tratamentos e às avaliações agronômicas.

Foram coletadas 20 amostras simples, a uma profundidade de $20 \mathrm{~cm}$ da superfície, para composição da amostra composta total, caracterizada como amostra representativa da área $\left(0,05 \mathrm{ha}^{-1}\right)$, para posterior análises físicas e químicas do solo em laboratório. A amostra foi acondicionada em saco plástico adequado (limpo) e devidamente identificado (Cantarutti, Alvarez V., Ribeiro, 1999).

A amostras do solo foram submetidas às análises no Laboratório de Análises de Solo do IFTO - Campus Araguatins. Os resultados foram expressos em volume e/ou em massa referente as subamostras de terra fina seca ao ar (TFSA), de acordo com a forma de medida da análise correspondente e em porcentagem para as análises de textura física do solo, conforme apresentado na Tabela 1 .

Tabela 1 - Resultado das análises químicas e físicas do solo

\begin{tabular}{|c|c|c|c|c|c|c|c|}
\hline Amostra & $\mathbf{p H}$ & $\mathbf{P}$ & $\mathbf{K}$ & $\mathbf{C a}$ & Mg & Al & $\mathbf{H}+\mathbf{A l}$ \\
\hline --- cm --- & - & \multicolumn{2}{|c|}{---- $\mathrm{mg} \mathrm{dm}^{-3}$---- } & \multicolumn{4}{|c|}{--------------- $\mathrm{cmol}_{\mathrm{c}} \mathrm{dm}^{-3}$-------------- } \\
\hline $0-20$ & 5,5 & 2,20 & 61 & 1,4 & 0,6 & 0,1 & 1,32 \\
\hline $\mathbf{S}$ & $\mathbf{T}$ & $\mathrm{V \%}$ & MO & \multicolumn{2}{|c|}{ Areia } & Argila & Silte \\
\hline $\begin{array}{ll}------\cdot \\
--1\end{array}$ & $\mathrm{l}_{\mathrm{c}} \mathrm{dm}^{-3}$ & $\begin{array}{c}--- \\
-\end{array}$ & $--\%$-- & \multicolumn{4}{|c|}{------------------- $\%$--------------------- } \\
\hline 2,16 & 3,48 & 62,03 & 1,84 & \multicolumn{2}{|c|}{78,19} & 11,44 & 10,37 \\
\hline
\end{tabular}

Fonte: Laboratório de análises de solos do IFTO - Campus Araguatins (2017)

O método utilizado para recomendação da Necessidade de Calagem (NC) foi o da neutralização do $\mathrm{Al}^{3+}$ e da elevação dos teores de $\mathrm{Ca}^{2+}{\mathrm{e} \mathrm{Mg}^{2+}}^{2+}$ (Alvarez., Ribeiro, 1999). Para correção do solo foi utilizado calcário dolomítico 70 dias antes da adubação fosfatada, de aspecto físico pó, e de composição com Poder Relativo de Neutralização Total (PRNT) mínimo de $80 \%$.

$\mathrm{O}$ valor da capacidade tampão do solo $(\mathrm{Y})$ foi de 1,0 , considerando a textura arenosa ( 0 a $15 \%$ de argila). Já para correção dos níveis de $\mathrm{Ca}$ e $\mathrm{Mg}$, foi considerada a exigência desses nutrientes (X) de 3,0 $\mathrm{cmol}_{\mathrm{c}} \mathrm{dm}^{-3}$, e valores máximos de saturação por $\mathrm{Al}^{3+}$ tolerado pela cultura (Mt) de $25 \%$, conforme recomendações para o Megathyrsus maximus cv. Mombaça (Alvarez, Ribeiro, 1999; Sousa, Lobato, 2004). A necessidade de calagem (em ton. ha ${ }^{-1}$ ) foi calculada pela seguinte fórmula: $\mathrm{NC}=\mathrm{Y}\left(\mathrm{Al}^{3+}-(\mathrm{Mt} \mathrm{x}\right.$ $\mathrm{T} / 100)+\left(\mathrm{X}-\left(\mathrm{Ca}^{2+}+\mathrm{Mg}^{2+}\right)\right)$, onde: $\mathrm{T}=$ Capacidade de troca de cátions (CTC efetiva) ou $\mathrm{S}+\mathrm{H}+\mathrm{Al}$.
A partir dos dados meteorológicos disponíveis, foram calculadas as médias mensais de temperatura, umidade relativa do ar e as médias mensais de precipitação, durante o período de outubro de 2017 a julho de 2018.

$\mathrm{O}$ delineamento experimental utilizado foi o de blocos casualizados (DBC), em esquema fatorial com dois fatores (4 níveis de $\mathrm{P}$ x 2 de calagem) e quatro repetições, totalizando 32 parcelas experimentais. $\mathrm{O}$ experimento foi composto por quatro diferentes níveis de fósforo $(0,30,80$ e $120 \mathrm{~kg}$ ha $^{-1}$ de $\mathrm{P}_{2} \mathrm{O}_{5}$ ), com e sem calagem, totalizando 8 tratamentos (T) experimentais: $0 \mathrm{~kg}$ Calcário e $0 \mathrm{~kg}$ $\mathrm{ha}^{-1}$ de $\mathrm{P}_{2} \mathrm{O}_{5}$ (T1); $1000 \mathrm{~kg}$ Calcário e $0 \mathrm{~kg} \mathrm{ha}^{-1}$ de $\mathrm{P}_{2} \mathrm{O}_{5}$ (T2); 0 kg Calcário e $30 \mathrm{~kg} \mathrm{ha}^{-1}$ de $\mathrm{P}_{2} \mathrm{O}_{5}$ (T3); $1000 \mathrm{~kg}$ Calcário e $30 \mathrm{~kg} \mathrm{ha}^{-1}$ de $\mathrm{P}_{2} \mathrm{O}_{5}$ (T4); $0 \mathrm{~kg}$ Calcário e $80 \mathrm{~kg} \mathrm{ha}^{-1}$ de $\mathrm{P}_{2} \mathrm{O}_{5}$ (T5); 1000 kg Calcário e $80 \mathrm{~kg} \mathrm{ha}^{-1}$ de $\mathrm{P}_{2} \mathrm{O}_{5}$ (T6); $0 \mathrm{~kg}$ Calcário e $120 \mathrm{~kg} \mathrm{ha}^{-1}$ de $\mathrm{P}_{2} \mathrm{O}_{5}$ (T7) e $1000 \mathrm{~kg}$ Calcário e $120 \mathrm{~kg} \mathrm{ha}^{-1}$ de $\mathrm{P}_{2} \mathrm{O}_{5}$ (T8). 
Passados setenta dias após a calagem para a correção da acidez do solo, foram realizadas as adubações com fonte de fósforo $(\mathrm{P})$ para correção da deficiência do nutriente no solo e avaliação das diferentes dosagens no desenvolvimento da forrageira. Também, foram realizadas as devidas correções da deficiência de potássio $(\mathrm{K})$ com doses idênticas para todas as parcelas, com $40 \mathrm{~kg} \mathrm{ha}^{-1} \mathrm{de}$ $\mathrm{K}_{2} \mathrm{O}$, considerando teores médios de disponibilidade de $\mathrm{K}$ no solo (61 $\mathrm{mg} \mathrm{dm}^{3}$ ), conforme interpretação do resultado da análise do solo, a fim de promover iguais condições de desenvolvimento para a cultura forrageira (Cantarutti et al., 1999).

A adubação fosfatada foi realizada durante a estação chuvosa, levando-se em consideração o nível do nutriente na análise de solo, sendo realizada entre 60 e 90 dias após a calagem, seguindo as recomendações de adubação para manutenção da forragem, em médio nível tecnológico, aplicado à espécie muito exigente em fertilidade do solo. Foi utilizado como fonte de P na adubação da pastagem, o Superfosfato Simples (SS), o qual apresenta garantias mínimas de $16 \%$ de $\mathrm{P}_{2} \mathrm{O}_{5}$ (sol. em $\mathrm{H}_{2} \mathrm{O}$ ) a $18 \%$ de $\mathrm{P}_{2} \mathrm{O}_{5}$ (sol. em CNA $+\mathrm{H}_{2} \mathrm{O}$ ). O SS apresentou teores totais de $18 \%$ de Cálcio $(\mathrm{Ca})$ e $11 \%$ de Enxofre (S) em sua composição (Alvarez, Ribeiro, 1999).

Os cortes mensais foram realizados em uma área útil de $1 \mathrm{~m}^{2}$ por parcela $\mathrm{A}$ coleta das amostras da forragem para análises das variáveis agronômicas em laboratório ocorreu 30 dias após o corte de uniformização da forragem (Jank et al., 2010). Para tanto, essas colheitas foram feitas manualmente, com o auxílio de uma tesoura de poda e de uma moldura de $1 \mathrm{~m}^{2}$.

Após os cortes da forragem, fez-se o acondicionamento das amostras em recipiente adequado (sacos de plástico) e posterior pesagem. As amostras foram identificadas e encaminhadas para o Laboratório de Bromatologia e Microbiologia de Alimentos (LBMA) do IFTO - Campus Araguatins, onde foram armazenadas em sacos de papel. Após o encaminhamento imediato para o laboratório foi retirada uma subamostra média de $500 \mathrm{~g}$ de cada tratamento para proceder com a pré-secagem em estufa de circulação forçada de ar por até 72 horas (2 a 3 dias) a uma temperatura média de $60^{\circ} \mathrm{C}$ (Mizubuti et al., 2009; Silva e Queiroz, 2002).

Considerando a dificuldade na mistura de materiais de diferentes tamanhos, as amostras da gramínea (poaceae) foram cortadas em tamanhos de 2,5 a 5,0 cm. Após a homogeneização, foram retiradas amostras compostas, as quais foram secas, moídas e peneiradas em peneira e $1 \mathrm{~mm}$ para facilitar a secagem e determinação da MS e MM da forragem (Mizubuti, 2009).

As variáveis analisadas foram: altura de plantas (AP); produção de matéria verde (MV); porcentagem de matéria seca (MS) e porcentagem de matéria mineral $(\mathrm{MM})$ da forragem. A altura média de plantas (AP) foi mensurada a partir do nível do solo até o ápice de plantas $(\mathrm{cm})$, obtendo-se três medidas por parcela, e totalizando doze medições por tratamento. A produção de matéria verde (MV) representa o peso $(\mathrm{kg})$ da forragem verde cortada a 50 cm acima no solo.

A determinação da porcentagem de matéria seca (MS) da forragem foi obtida pela eliminação do conteúdo de água, por meio da pré-secagem e da secagem definitiva (Mizubuti, 2009). A porcentagem de matéria mineral (MM) foi obtida após a remoção de toda a umidade da forragem e do material orgânico (gorduras, proteínas, carboidratos, vitaminas, ácidos orgânicos e outros) após ter sido aquecido a alta temperatura. A MM contém os cátions: cálcio, potássio, sódio, magnésio, ferro, cobre, cobalto, alumínio; e ânions: sulfato cloreto, silicato e fosfato, principalmente (Silva, Queiroz, 2002).

A altura média das plantas (AP) foi mensurada com o auxílio de uma trena graduada, de $5 \mathrm{~m}$ de comprimento, sendo realizada três medições por área útil da parcela, totalizando doze medidas amostrais simples por tratamento, nas três avaliações de campo (Jank et al., 2010).

A massa verde (MV) da forragem foi determinada com o auxílio de um quadrado de 1 x 1 $\mathrm{m}$, o qual foi lançado na área útil, coletando-se uma amostra por parcela, totalizando quatro amostras por tratamento. O corte da forragem, delimitado pelo 
quadrado foi feito a uma altura média de pastejo de $50 \mathrm{~cm}$ acima do solo, nas três coletas de campo (Jank et al., 2010).

Após feitos os cortes de amostragem na forragem, a área experimental foi pastejada por animais (bovinos) em fase de recria. Posteriormente, foi realizado o corte de uniformização das parcelas a uma altura de $50 \mathrm{~cm}$ acima do nível do solo.

As análises estatísticas foram realizadas com o auxílio do software SISVAR. Os resultados das análises laboratoriais e de campo foram submetidos à análise de variância e as médias comparadas pelo teste de Scott-Knott ao nível de 5\% de probabilidade (Ferreira, 2014).

O solo foi classificado do tipo arenoso (areia franca), quanto à classe textural, por apresentar menos de $15 \%$ de argila em sua composição. Os resultados das análises das amostras de solo na camada de 0 a $20 \mathrm{~cm}$ demonstraram alto teor $(>1,5)$ de matéria orgânica (MO), baseado no grupamento da classe textural do solo. Devido os teores adequados a altos de matéria orgânica situar-se entre 1,5 a 5,2, de acordo com a recomendação para cada classe textural de solo (arenosa, média, argilosa e muito argilosa), de acordo com Sousa e Lobato (2004).

A média de temperatura durante os meses de novembro de 2017 a abril de 2018 (período coincidente com a correção do solo, adubação e cortes da pastagem) foi de $26,35^{\circ} \mathrm{C}$, com o menor valor no mês de fevereiro de $2018 \mathrm{com} 25,5^{\circ} \mathrm{C}$. Já a média de umidade relativa nesse mesmo período correspondeu a 75,85 \%, obtendo assim, a maior média em fevereiro de 2018, com 80,4\% de umidade relativa, revelando-se valores inversamente proporcional à temperatura, porém, ambos indispensáveis para manutenção do equilíbrio ambiental do sistema de produção, conforme informações apresentadas no Gráfico 1.

Durante o período experimental (novembro de 2017 a abril de 2018), foram obtidas precipitações acumuladas de $1547 \mathrm{~mm}$, as quais contribuiram satisfatoriamente para o desenvolvimento e manutenção da pastagem, de cordo com informações do Gráfico 2.

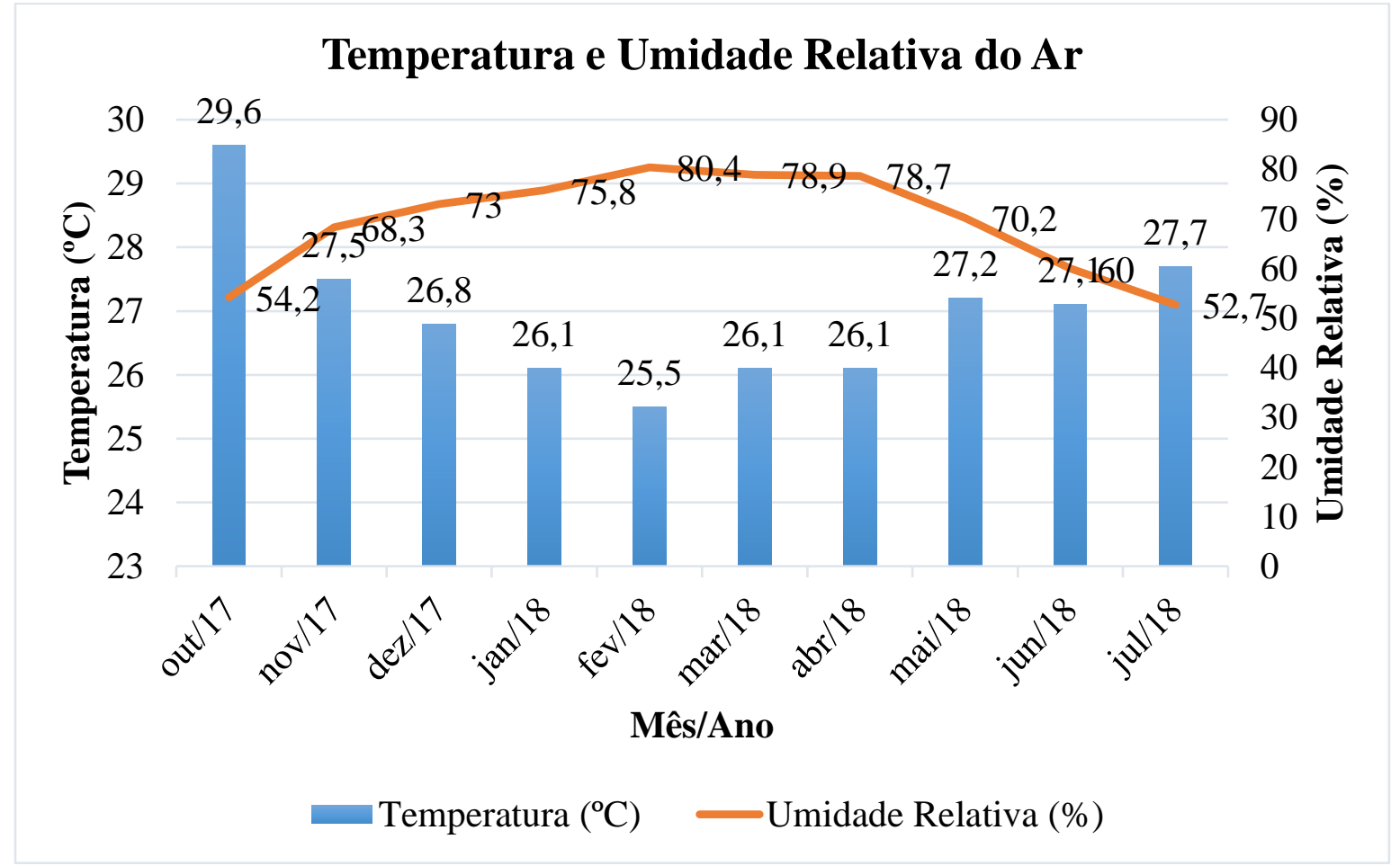

Figura 1 - Média mensal de temperatura e umidade relativa do ar. Fonte: INMET (2018) 


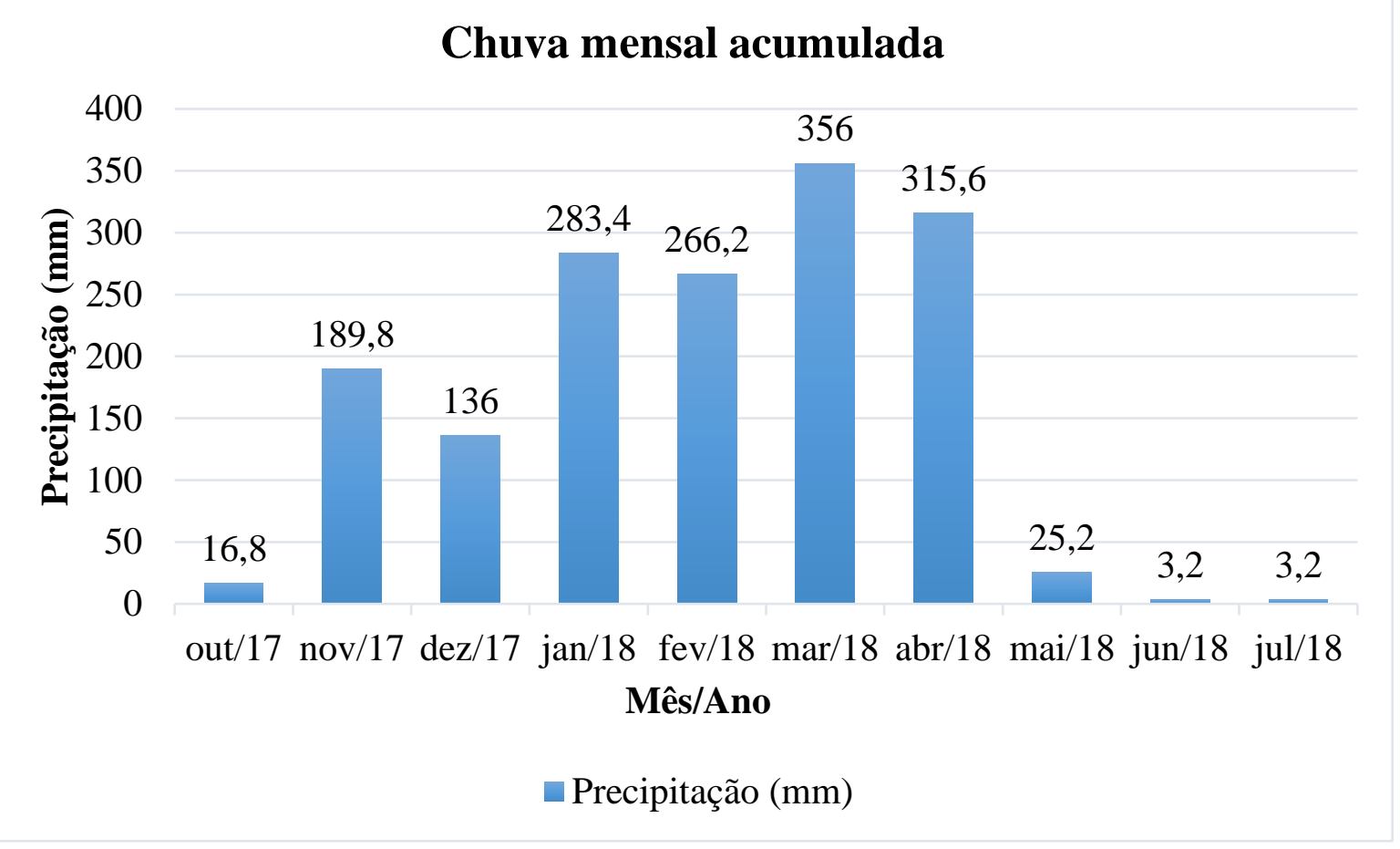

Figura 2 - Precipitação média mensal. Fonte: INMET (2018)

Verificou-se que não houve efeito significativo para altura de plantas (AP) e produção de matéria verde (MV) do Megathyrsus maximus cv. Mombaça, quando submetido a diferentes doses de fósforo (P) com e sem calagem (Tabela 2). Este efeito pode estar relacionado com a disponibilidade limitada de $\mathrm{P}$ no solo e o consequente baixo efeito residual pela falta de correção inicial na fase de formação, aliado ao curto espaço de tempo de avaliação da forragem. No entanto, houve diferença significativa entre os blocos avaliados em nível de $5 \%$ e $1 \%$ de probabilidade para AP e MV, respectivamente. Estes indicadores resultaram na assertividade do delineamento experimental utilizado em área de baixo controle ambiental.

Carneiro et al. (2017), avaliando o efeito de doses e fontes de diferentes fertilizantes fosfatados na adubação de estabelecimento do capim Mombaça, concluíram que, além de promover melhor perfilhamento e produção fotossintética, ocorreu uma maior altura de plantas, a produção de massa verde e, consequentemente, uma maior produção de massa seca utilizando o superfosfato simples (SS), com a menor dosagem entre os fertilizantes avaliados.

Os níveis de $\mathrm{P}$ com e sem calagem não diferiram estatisticamente para AP e produção de MV, conforme dados apresentados na Tabela 3. Isso pode estar associado à falta de incorporação mecânica do calcário no solo, prática que promove o aumento da superfície de contato do corretivo com as raízes e, consequentemente, o melhor aproveitamento pelas plantas forrageiras.

A profundidade efetiva de incorporação natural do calcário na adubação de superfície situa-se entre os 5 e $10 \mathrm{~cm}$ superficiais; no entanto, a incorporação de camadas profundas, na fase de manutenção da forragem, deve-se associar a aplicação de gesso à calagem (Cantarutti et al., 1999). 
Tabela 2 - Resumo das análises de variância da altura de plantas e da produção de matéria verde do capim Mombaça submetido a diferentes doses de fósforo $(\mathrm{P})$ com e sem calagem

Fonte de Variação
Graus de Liberdade

\begin{tabular}{cccc}
\hline Doses de P & 3 & $\mathrm{~ns}$ & $\mathrm{~ns}$ \\
Calcário & 1 & $\mathrm{~ns}$ & $\mathrm{~ns}$ \\
Blocos & 3 & $*$ & $* *$ \\
Doses P x Calcário & 3 & $\mathrm{~ns}$ & $\mathrm{~ns}$ \\
Erro & 21 & - & - \\
Total & 31 & - & - \\
\hline CV (\%) & - & $\mathbf{5 , 9 1}$ & $\mathbf{2 1 , 5 8}$ \\
\hline Média geral & - & $\mathbf{9 1 , 8 7}$ & $\mathbf{0 , 9 0}$ \\
\hline Número de observações & & $\mathbf{3 2}$ & \\
\hline
\end{tabular}

\begin{tabular}{cccc}
\hline Doses de P & 3 & $\mathrm{~ns}$ & $\mathrm{~ns}$ \\
Calcário & 1 & $\mathrm{~ns}$ & $\mathrm{~ns}$ \\
Blocos & 3 & $*$ & $* *$ \\
Doses P x Calcário & 3 & $\mathrm{~ns}$ & $\mathrm{~ns}$ \\
Erro & 21 & - & - \\
Total & 31 & - & - \\
\hline CV (\%) & - & $\mathbf{5 , 9 1}$ & $\mathbf{2 1 , 5 8}$ \\
\hline Média geral & - & $\mathbf{9 1 , 8 7}$ & $\mathbf{0 , 9 0}$ \\
\hline Número de observações & & $\mathbf{3 2}$ & \\
\hline
\end{tabular}

Número de observações

Altura de plantas

(cm)

\section{Matéria verde}

$\left(\mathrm{kg} \mathrm{m}^{-2}\right)$

Nota: $(*)$ significativo ao nível de $5 \%(\mathrm{P}<0,05)$ de probabilidade pelo teste $\mathrm{F}$. $(* *)$ significativo ao nível de $1 \%(\mathrm{P}<0,01)$ de probabilidade pelo teste F. (ns) não significativo.

Tabela 3 - Valores médios dos desdobramentos das doses de fósforo $(\mathrm{P})$ para altura de plantas e produção de matéria verde do capim Mombaça com e sem correção do solo com calcário

\begin{tabular}{ccccc}
\hline \multirow{2}{*}{$\begin{array}{c}\text { Doses de } \mathbf{P} \\
\left(\mathbf{k g ~ h a}^{-1} \mathbf{P}_{\mathbf{2}} \mathbf{O}_{\mathbf{5}}\right)\end{array}$} & \multicolumn{2}{c}{ Altura de plantas $\mathbf{( c m})$} & \multicolumn{2}{c}{ Matéria verde $\mathbf{( k g ~ m}^{\mathbf{- 2}} \mathbf{)}$} \\
\cline { 2 - 5 } & Sem Calcário & Com Calcário & Sem Calcário & Com Calcário \\
\hline 0 & $88,75 \mathrm{Aa}$ & $96,25 \mathrm{Aa}$ & $0,94 \mathrm{Aa}$ & $0,74 \mathrm{Aa}$ \\
30 & $92,50 \mathrm{Aa}$ & $91,25 \mathrm{Aa}$ & $0,86 \mathrm{Aa}$ & $0,99 \mathrm{Aa}$ \\
80 & $93,75 \mathrm{Aa}$ & $91,25 \mathrm{Aa}$ & $1,04 \mathrm{Aa}$ & $1,02 \mathrm{Aa}$ \\
120 & $92,50 \mathrm{Aa}$ & $88,75 \mathrm{Aa}$ & $0,80 \mathrm{Aa}$ & $0,79 \mathrm{Aa}$ \\
\hline
\end{tabular}

$\begin{array}{lll}\text { CV }(\%) & \mathbf{5 , 9 1} & \mathbf{2 1 , 5 8}\end{array}$

Nota: As médias seguidas de mesma letra maiúscula na coluna e de mesma letra minúscula na linha não diferem estatisticamente entre si, pelo teste de Scott-Knott, a 5\% de probabilidade.

Oliveira et al. (2007), avaliando o efeito residual de fertilizantes fosfatados solúveis na recuperação Brachiaria brizantha cv. Marandu em Neossolo Quartzarênico, concluíram que a calagem associada a adubação fosfatada ( $80 \mathrm{~kg} \mathrm{ha}^{-1}$ ano) a cada dois anos favoreceu a produção de forragem e proporcionou aumento significativos nos teores de nutrientes e redução do alumínio no solo. A resposta da adubação foi melhor no segundo ano, podendo ocorrer também maiores produções a partir do primeiro ano de cultivo, utilizando adubações com superfosfatos.

Verificou-se que houve efeito significativo para as diferentes doses de $\mathrm{P}$ e entre blocos para porcentagem de matéria seca (MS) do capim Mombaça. Porém, não houve diferença significativa entre a correção ou não do solo com a calagem, nem de suas interações com as doses de P, conforme informações apresentadas na Tabela 4.

Tanto as doses de $\mathrm{P}$ com e sem calagem, bem como suas interações, não tiveram efeitos significativos para porcentagem de matéria mineral (MM). Fato esse, possivelmente, decorrente da alta saturação por bases (V\%), apresentados na análise de solo (Tabela 1), encontrando-se na faixa ideal para espécie forrageira exigente em fertilidade do solo $(62,03 \%)$.

Alvares V. e Ribeiro (1999); Sousa e Lobato (2004) destacam que as faixas adequadas de saturação por bases estão entre $40 \%$ e $60 \%$ para plantas forrageiras exigentes e muito exigentes, respectivamente. 
Tabela 4 - Resumo das análises de variância da porcentagem de matéria seca e de matéria mineral do capim Mombaça submetido a diferentes dosagens de fósforo (P) com e sem calagem
FV
GL Matéria seca (\%)
Matéria mineral (\%)

\begin{tabular}{cccc}
\hline Doses de P & 3 & $*$ & $\mathrm{~ns}$ \\
Calcário & 1 & $\mathrm{~ns}$ & $\mathrm{~ns}$ \\
Blocos & 3 & $*$ & $\mathrm{~ns}$ \\
Doses de P x Calcário & 3 & $\mathrm{~ns}$ & $\mathrm{~ns}$ \\
Erro & 21 & - & - \\
\hline Total & $\mathbf{3 1}$ & - & - \\
\hline CV $(\%)$ & & 7,01 & 26,87 \\
\hline Média geral & 24,47 & 10,23 \\
\hline Número de observações & & $\mathbf{3 2}$ \\
\hline
\end{tabular}

Nota: (*) significativo ao nível de $5 \%(\mathrm{p}<0,05)$ de probabilidade pelo teste $\mathrm{F}$. (ns) não significativo.

Os níveis de $80 \mathrm{~kg} \mathrm{ha}^{-1}$ de $\mathrm{P}_{2} \mathrm{O}_{5}$ e $120 \mathrm{~kg} \mathrm{ha}^{-1}$ de $\mathrm{P}_{2} \mathrm{O}_{5}$ obtiveram médias superiores em porcentagem de matéria seca (MS), diferindo estatisticamente da dose de $30 \mathrm{~kg} \mathrm{ha}^{-1}$ de $\mathrm{P}_{2} \mathrm{O}_{5}$ e do tratamento testemunha (Gráfico 3). Estes indicadores apresentaram associação com as recomendações de Vilela et al. (2004), ao preconizar a dose de $80 \mathrm{~kg} \mathrm{ha}$ ${ }^{1}$ de $\mathrm{P}_{2} \mathrm{O}_{5}$ para espécies forrageiras muito exigentes, cultivadas em solos arenosos de maneira geral.
Após a correção do solo com calcário, a dose de $30 \mathrm{~kg} \mathrm{ha}^{-1}$ de $\mathrm{P}_{2} \mathrm{O}_{5}$ proporcionou maior porcentagem de MS, em relação a mesma dose sem a prática de calagem. Já quanto a porcentagem de MM não houve diferença significativa entre as doses de $\mathrm{P}$ e de suas respectivas interações com e sem a calagem, conforme informações apresentadas na Tabela 5.

Tabela 5 - Valores médios dos desdobramentos das doses de fósforo (P) para porcentagem de matéria seca (MS) e matéria mineral (MM) do capim Mombaça com e sem correção do solo com calcário

\begin{tabular}{|c|c|c|c|c|}
\hline \multirow{2}{*}{$\begin{array}{c}\text { Doses de P } \\
\left(\mathrm{kg} \mathrm{P}_{2} \mathrm{O}_{5} \mathrm{ha}^{-1}\right) \\
\end{array}$} & \multicolumn{2}{|c|}{ MS (\%) } & \multicolumn{2}{|c|}{ MM (\%) } \\
\hline & Sem Calcário & Com Calcário & Sem Calcário & Com Calcário \\
\hline 0 & $23,78 \mathrm{Ba}$ & $23,06 \mathrm{Aa}$ & 9,985 Aa & 9,97 Aa \\
\hline 30 & $21,55 \mathrm{Bb}$ & $24,51 \mathrm{Aa}$ & $10,44 \mathrm{Aa}$ & 9,89 Aa \\
\hline 80 & $25,70 \mathrm{Aa}$ & $26,08 \mathrm{Aa}$ & $9,71 \mathrm{Aa}$ & $9,80 \mathrm{Aa}$ \\
\hline 120 & $26,27 \mathrm{Aa}$ & $24,83 \mathrm{Aa}$ & $10,09 \mathrm{Aa}$ & $11,97 \mathrm{Aa}$ \\
\hline CV (\%) & \multicolumn{2}{|c|}{7,01} & \multicolumn{2}{|c|}{26,87} \\
\hline
\end{tabular}

Nota: As médias seguidas de mesma letra maiúscula na coluna e de mesma letra minúscula na linha não diferem estatisticamente entre si, pelo teste de Scott-Knott, a 5\% de probabilidade.

Magalhães et al. (2007), ao avaliar a maiores produções de MS quando submetida à influência do fósforo e do nitrogênio na produção da adubação nitrogenada. Pois, à medida que a forrageira braquiária, concluíram que a pastagem obtém se desenvolve, sobretudo na fase de pastejo, a 
demanda de $\mathrm{P}$ diminui, enquanto as de $\mathrm{N}$ e $\mathrm{K}$ aumentam (Cantarutti et al., 1999). Nesta perspectiva, Vilela et al. (2004), ao avaliar níveis de adubação de manutenção com $\mathrm{N}$ e $\mathrm{K}$ na produção de $\mathrm{MS}$ de Brachiaria decumbens, concluíram que a falta de reposições bienais de $\mathrm{P}$ e das anuais de $\mathrm{N}$ e $\mathrm{K}$ resultaram em reduções semelhantes no rendimento de MS, pois se houver deficiência de algum nutriente no solo, a adubação de manutenção com $\mathrm{P}$ pode ser comprometida. Isso significa que em três anos pode ocorrer perdas superiores à $30 \%$ da produção total de MS, quando não satisfeita essa limitação.

O M. maximus cv. Mombaça apresentou melhores resultados produtivos com as doses de 80 $\mathrm{kg} \mathrm{ha}^{-1}$ de $\mathrm{P}_{2} \mathrm{O}_{5}$ e $120 \mathrm{~kg} \mathrm{ha}^{-1}$ de $\mathrm{P}_{2} \mathrm{O}_{5}$, em produção de matéria verde e de matéria seca. Porém, com a dose de $80 \mathrm{~kg} \mathrm{ha}^{-1}$ de $\mathrm{P}_{2} \mathrm{O}_{5}$, houve destaque em produção de matéria seca com a calagem. A pastagem obteve incremento de produtividade e em porcentagem de matéria seca com a dose de $30 \mathrm{~kg} \mathrm{ha}^{-1}$ de $\mathrm{P}_{2} \mathrm{O}_{5}$ na fase de manutenção, quando precedida da correção do solo com a calagem, nas condições ambientais locais de Cerrado-Amazônia do município de Araguatins TO.

\section{AGRADECIMENTOS}

Ao Instituto Federal de Educação, Ciência e Tecnologia do Tocantins (IFTO) - Campus Araguatins pelo suporte e apoio estrutural durante a realização deste trabalho.

\section{FINANCIAMENTO}

Esta pesquisa não recebeu financiamento de agências de fomento ou do setor privado.

\section{REFERÊNCIAS BIBLIOGRÁFICAS}

Alvarez V., V. H; Ribeiro, A. C. (1999). Calagem. In: Ribeiro, A. C., Guimarães, P. T. G., Alvarez V. V. H. (eds). Recomendações para o uso de corretivos e fertilizantes em Minas Gerais - $5^{\text {a }}$ Aproximação. Comissão de Fertilidade do Solo do Estado de Minas Gerais: Viçosa, MG. p. 43-60.

Cantarutti, R. B.; Martins, C. E.; Carvalho, M. M. et al. (1999). Pastagens. In: Ribeiro, A. C., Guimarães,
P. T. G., Alvarez V. V. H. (eds). Recomendações para o uso de corretivos e fertilizantes em Minas Gerais $-\mathbf{5}^{\mathbf{a}}$ Aproximação. Comissão de Fertilidade do Solo do Estado de Minas Gerais: Viçosa, MG. p. 332-341.

Cantarutti, R. B.; Alvarez V., V. H.; Ribeiro, A. C (1999). Amostragem do solo. In: Ribeiro, A. C., Guimarães, P. T. G., Alvarez V. V. H. (eds). Recomendações para o uso de corretivos e fertilizantes em Minas Gerais - $5^{\mathbf{a}}$ Aproximação. Comissão de Fertilidade do Solo do Estado de Minas Gerais: Viçosa, MG. p. 13-20.

Carneiro, J. S. S.; Silva, P. S. S.; Santos, A. C. et al. (2017). Resposta do campim Mombaça sob efeito de fontes e doses de fósforo na adubação de formação. Jornal of Bioenergy and Food Science, v.4, n.1, p.12-25. DOI 10.18067/jbfs.v4i1.117.

EMBRAPA (2018). Clima. Empresa Brasileira de Pesquisa Agropecuária. Disponível em: https://www.cnpf.embrapa.br/pesquisa/efb/clima.ht m.

Ferreira, D. F. (2014). Sisvar: a Guide for its Bootstrap procedures in multiple comparisons. Ciência e Agrotecnologia (Online), vol.38, n.2, p. 109-112. ISSN 1413-7054.

Fonseca, D. M.; Martuscello, J. A. (2010). Plantas forrageiras. Dilermando Miranda da Fonseca, Janaina Azevedo Martuscello. Ed. UFV: Viçosa, MG. 537p.

IBGE (2017). Resultados definitivos da produção agropecuária. Censo Agropecuário 2017. Instituto Brasileiro de Geografia e Estatística. Brasília, DF, Brasil. Disponível em: https://censos.ibge.gov.br/agro/2017/templates/censo _agro/resultadosagro/informativos.html.

Jank, L.; Fonseca, D. M.; Martuscello, J. A. et al. (2010). Panicum maximum. In: Delermando Miranda da Fonseca, Janaina Azevedo Martuscello (eds). Plantas Forrageiras. Ed. UFV: Viçosa, MG. 537p.

Lopes, A. S.; Alvarez V., V. H. (1999). Apresentação dos resultados das análises de solo. In: Ribeiro, A. C., Guimarães, P. T. G., Alvarez V. V. H. (eds). Recomendações para o uso de corretivos e 
fertilizantes em Minas Gerais - $5^{\mathbf{a}}$ Aproximação. Comissão de Fertilidade do Solo do Estado de Minas Gerais: Viçosa, MG. p. 21-24.

Magalhães, A. F.; Pires, A. J. V.; Carvalho, G. G. P. et al. (2007). Influência do nitrogênio e do fósforo na produção de capim braquiária. Revista Brasileira de Zootecnia, v.36, n.5, p. 1240-1246.

MAPA (2018). Complexo carnes. Ministério da Agricultura, Pecuária e Abastecimento. Disponível em: http://www.agricultura.gov.br/assuntos/politicaagricola/todas-publicacoes-de-politicaagricola/sumarios-executivos-de-produtosagricolas/carnes.pdf/view.

Matsuda (2016). Base alimentar da pecuária em países de clima tropical. In: Sementes para pastagem. Portfólio. Álvares Machado, SP. 55p.

Mizubuti, I. Y.; Pinto, A. P.; Pereira, E. S. et al. (2009). Métodos laboratoriais de avaliação de alimentos para animais. Londrina: EDUEL. 228p.

Oliveira, P. P. A.; Oliveira, W. S.; Corsi, M. (2007). Efeito residual de fertilizantes fosfatados solúveis na recuperação de pastagem de Brachiaria brizanta cv. Marandu em Neossolo Qartzarênico. Revista Brasileira de Zootecnia, v. 36, n.6, p. 1715-1728. ISSN (Online) 1806-9290.

Silva, D. J.; Queiroz, A. C. (2002). Análise de alimentos: métodos químicos e biológicos. 3. ed. Viçosa: UFV. 235p.

Sousa, D. M. G; Lobato, E. (2004). Cerrado: correção do solo e adubação. Djalma Martinhão Gomes de Sousa, Edson Lobato (eds). 2 ed. Brasília, DF: Embrapa Informação Tecnológica. 416p.

USDA (2018). Livestock and Poultry World Markests and Trade. United States Department of Agriculture. Disponível em: https://www.fas.usda.gov/data/livestock-andpoultry-world-markets-and-trade.

Vilela, L. et al. (2004). Calagem e adubação para pastagens. In: Djalma Martinhão Gomes de Sousa, Edson Lobato (eds). Cerrado: correção do solo e adubação. $2^{a}$ ed. Brasília, DF: Embrapa Informação Tecnológica. p. 367-382. 